\title{
Involvement of the Nucleus Accumbens and Medial Prefrontal Cortex in the Expression of Conditioned Hyperactivity to a Cocaine- Associated Environment in Rats
}

\author{
Teresa R. Franklin, Ph.D., and Jonathan P. Druhan, Ph.D.
}

This study examined the roles of the nucleus accumbens $(N A c)$, medial prefrontal cortex, basolateral amygdala, and ventral subiculum of the hippocampus in the expression of Pavlovian conditioned hyperactivity responses to cocainerelated stimuli. This was accomplished by pharmacologically inhibiting these regions prior to drug-free tests for conditioned hyperactivity in an environment previously associated with cocaine. The results indicate that conditioned hyperactivity could be disrupted by infusions of the GABA$B$ agonist, baclofen $(0.2 \mathrm{nmol} / 0.5 \mu \mathrm{l} / \mathrm{side})$ into the $N A c$, or completely blocked by infusions of the GABA-A agonist, muscimol (0.1 and $0.2 \mathrm{nmol} / 0.5 \mu \mathrm{l} / \mathrm{side}$ ) into the medial prefrontal cortex. In contrast, conditioned hyperactivity was unaffected by pharmacological inhibition of the basolateral amygdala, the ventral subiculum, or sites dorsal to the NAc or prefrontal cortex. These findings suggest that the NAc and the prefrontal cortex are crucial elements of the neural circuitry underlying the expression of Pavlovian conditioned responses to cocaine-related stimuli.

[Neuropsychopharmacology 23:633-644, 2000]

(C) 2000 American College of Neuropsychopharmacology.

Published by Elsevier Science Inc.
KEY WORDS: Pavlovian conditioning; Drug abuse; GABA agonist; Cingulate cortex; Locomotion; Rats

Environmental stimuli associated with cocaine use can elicit a variety of conditioned physiological and subjective responses in abstinent cocaine addicts (Childress et al. 1999; Newlin 1992). These Pavlovian conditioned responses may contribute to the maintenance of drug-taking habits in active cocaine users, and promote relapse in

From the Neuroscience Graduate Program, MCP-Hahnemann University, Philadelphia, PA (TRF); and the Center for Neurobiology and Behavior, Department of Psychiatry, University of Pennsylvania School of Medicine, Philadelphia, PA (JPD). TRF is currently at the Treatment Research Center, Department of Psychiatry, University of Pennsylvania School of Medicine, Philadelphia, PA 19104.

Address correspondence to: Dr. J.P. Druhan, VA Medical Center, Mail Code 151, University and Woodland Aves, Philadelphia, PA 19104.

Received 7 March 2000; revised 1 June 2000; accepted 13 June 2000. detoxified addicts. In rats, environments associated with cocaine evoke conditioned locomotor activation in the absence of the drug (Barr et al. 1983; Cervo and Samanin 1996; DiCiano et al. 1998a; Stewart et al. 1984). This Pavlovian conditioned behavioral activation may be analogous to some of the conditioned subjective and physiological responses elicited by cocaine-related stimuli in human drug addicts (Pert 1994). Accordingly, studies of the neurobiological mechanisms underlying conditioned behavioral activation in rats may provide valuable information that could facilitate the development of pharmacological treatments for cocaine addiction.

Several lines of evidence suggest that the nucleus accumbens (NAc) may regulate the expression of conditioned responses to stimuli associated with cocaine or other psychostimulants. For example, 6-OHDA lesions of mesoaccumbens dopamine terminals post-conditioning can interfere with conditioned hyperactivity elicited 
by an environment repeatedly paired with amphetamine (Gold et al. 1988). Moreover, exposure to cocaine- or amphetamine-related cues increases dopamine release within the NAc (DiCiano et al. 1998a,b; Fontana et al. 1993; Gratton and Wise 1994), alters NAc cell firing (Bowman et al. 1996; Giampoala et al. 1999), and induces conditioned increases in Fos-related protein within the caudal NAc (Franklin and Druhan 2000; Neisewander et al. 2000; although see Brown and Fibiger 1992). Together, these studies suggest that the NAc may be important for the expression of conditioned hyperactivity responses to psychostimulantpaired stimuli.

Cortical and limbic regions that project to the NAc also may regulate conditioned responses to psychostimulant-related cues. Indeed, lesions or pharmacological manipulations of the medial prefrontal cortex (mPFC), the basolateral amygdala (Bl), and the ventral subiculum of the hippocampus (vSub) disrupt the stimulus control of operant drug-seeking responses measured in place-preference, conditioned reinforcement, or self-administration procedures (Brown and Fibiger 1993; Hiroi and White 1991; Hitchcott and Phillips 1997, 1998; Isaac et al. 1989; Tzschentke and Schmidt 1998; Whitelaw et al. 1996; Young and Deutch 1998). However, each structure appears to regulate different aspects of stimulus-controlled responding, as central manipulations that disrupt responses in one learning paradigm often do not affect performance in other conditioning tasks. For example, lesions of the $\mathrm{Bl}$ or vSub disrupt operant responses for a food-related conditioned reinforcer without affecting Pavlovian conditioned approach responses to a food-related stimulus (Everitt et al. 1999). In contrast, lesions of the anterior cingulate area and the NAc core abolish Pavlovian conditioned approach responses without influencing responding for a food-related conditioned reinforcer (Bussey et al. 1997; Everitt et al. 1999). Studies of conditioned drug effects further indicate that $\mathrm{Bl}$ lesions can block the expression of conditioned preferences for a psychostimulant-associated environment without affecting conditioned hyperactivity in a stimulant-paired context (Ahmed et al. 1995; Brown and Fibiger 1993). This latter dissociation could reflect a greater dependence of conditioned hyperactivity responses on cingulate processes involved in Pavlovian conditioning. Accordingly, conditioned hyperactivity might be more sensitive to disruption by manipulations of the anterior cingulate/mPFC than by $\mathrm{Bl}$ or vSub manipulations.

The experiments described below tested this prediction by pharmacologically inhibiting the $\mathrm{Bl}$, the vSub, and the cingulate/prelimbic regions of MPFC with the $\mathrm{GABA}_{\mathrm{A}}$ agonist muscimol (Izquierdo et al. 1997; Martin 1991; Muller et al. 1997) prior to testing rats for conditioned hyperactivity in a cocaine-associated environment. The absence of conditioned hyperactivity follow- ing inhibition of one of these sites would suggest that the region regulated the expression of Pavlovian conditioned responses to cocaine-associated stimuli. The effects of inhibiting the NAc were also assessed to verify a role for this structure in conditioned hyperactivity. The $\mathrm{GABA}_{\mathrm{B}}$ agonist baclofen was used to inactivate the NAc because $95 \%$ of cells in this region are GABAergic, and an agonist acting on $\mathrm{GABA}_{\mathrm{B}}$ autoreceptors might inhibit the output of this region more effectively than muscimol. $\mathrm{GABA}_{\mathrm{B}}$ agonists also can inhibit the release of excitatory amino acids from afferent terminals within the NAc (Shi and Rayport 1994; Uchimura and North 1991), thus ensuring a strong inhibition of neuronal activity in this region.

\section{MATERIALS AND METHODS}

\section{Subjects}

Male Wistar rats (Charles River, Wilmington, MA), weighing 275-300 grams at the start of the experiment were singly housed in clear plastic cages in an AAALAC animal care facility maintained at $21^{\circ} \mathrm{C}$. Food and water were available ad libitum throughout the experiment. Experimental procedures were conducted at the same time each day during the light phase of the light/ dark cycle (lights on at 7:00 AM). All procedures were approved by an Institutional Animal Care and Use Committee in accordance with NIH guidelines.

\section{Surgery and Histology}

Surgeries were conducted one week after the rats' arrival in the animal care facility. Rats were anesthetized with sodium pentobarbital $(50 \mathrm{mg} / \mathrm{kg}$, i.p.) and placed in a stereotaxic apparatus for cannula implantation. Twentytwo gauge stainless-steel guide cannulae were then implanted bilaterally into the NAc, $\mathrm{mPFC}, \mathrm{Bl}$, or vSub. Coordinates (expressed relative to Bregma, the skull midline, and the skull surface (Paxinos and Watson 1998) were as follows: NAc, 1.6, $\pm 3.0,-6.0 ; \mathrm{mPFC}, 2.7, \pm 1.7$, $-3.5 ; \mathrm{Bl},-2.6, \pm 5.0,-7.4 ; \mathrm{vSub},-5.6, \pm 4.6,-8.5$. Additional control animals had cannulae implanted $3 \mathrm{~mm}$ dorsal to the NAc or $2 \mathrm{~mm}$ dorsal to the $\mathrm{mPFC}$. Cannulae aimed at or above the NAc and mPFC were implanted at a $15^{\circ}$ angle to avoid contact with the ventricle and to provide adequate room on the skull for the cannula and obturators. Dental cement was used to anchor cannulae to four jewelers screws set in the rats' skulls. Stainless-steel obturators were inserted with the tips extending $1 \mathrm{~mm}$ below the end of the guide cannulae. Following surgery, rats were treated with the topical antibiotic neomycin and the analgesic Flumeglumine $(1.0 \mathrm{mg} / \mathrm{kg})$.

All cannula placements were verified at the end of each experiment. To accomplish this, the rats were deeply anesthetized with sodium pentobarbital (100 
$\mathrm{mg} / \mathrm{kg}$, i.p.), and $0.5 \mu \mathrm{l}$ of $2 \%$ Pontamine Sky Blue was infused into each injection site over a $60 \mathrm{sec}$ period. The injectors were left in place for an additional 60 seconds to allow the dye to diffuse into the tissue, and the brains were then removed and frozen in $-70^{\circ}$ isopentane. The brains were later sliced into $40 \mu \mathrm{m}$ coronal sections on a cryostat, and every third section was mounted on gelatin-coated slides and stained with neutral red for subsequent microscopic verification of the injection site.

\section{Apparatus}

Behavioral testing was conducted in 8 Plexiglas chambers $(40 \times 40 \times 40 \mathrm{~cm}$; San Diego Instruments Inc., San Diego, CA), each equipped with 16 pairs of photocell sources and detectors stationed $3.5 \mathrm{~cm}$ above the floor and $3.5 \mathrm{~cm}$ apart around the perimeter. The photocell sources and detectors were connected via an interface to an IBM 486 computer with PAS software (San Diego Instruments Inc., San Diego, CA) that recorded interruptions of the photocell beams. The chambers were contained within a small, dimly lit room with white noise $(70 \mathrm{~dB})$ present to mask any extraneous sounds.

\section{Behavioral Conditioning Procedures}

A separate experiment was conducted for each CNS region examined in this study. Each experiment consisted of a 14-day pairing phase followed by a test for conditioned hyperactivity. During the pairing phase, the rats were brought to the laboratory on every second day and given a sham central infusion followed by an i.p. injection. The sham infusions involved removal of the obturators from the guide cannulae and attachment of infusion lines. These infusion lines remained in place for 120 seconds while the rats moved freely within a 28 $\times 18 \times 12 \mathrm{~cm}$ Plexiglas chamber. The infusion lines were then removed and replaced by obturators. Fifteen minutes later, rats assigned to the 'Paired' group were injected with cocaine $(10 \mathrm{mg} / \mathrm{kg}$, i.p.) and rats assigned to the 'Unpaired' group were given i.p. injections of saline. The rats were then placed immediately into the activity chambers where horizontal activity was measured for $60 \mathrm{~min}$.

All rats were given additional i.p. injections in the colony room environment on the remaining days of the pairing phase. Rats in the Unpaired group were injected with $10.0 \mathrm{mg} / \mathrm{kg}$ cocaine on these days, whereas rats in the Paired group received only saline. Overall, rats in the Paired group received seven injections of cocaine in the test environment and seven saline injections in the colony room, whereas rats in the Unpaired group received seven cocaine injections in the colony room and only saline in the test environment. Control groups that receive saline in both environments were not included in this study as such groups rarely differ from Unpaired groups during tests for conditioning, and GABA-ergic effects in these control rats would likely be redundant with those measured with Unpaired rats. Moreover, dose response experiments assessing unconditioned locomotor activity after infusions of baclofen into the NAc or muscimol into the mPFC (described below) eliminated the need for this control group.

\section{Test for Conditioned Hyperactivity}

Rats were tested for conditioned hyperactivity in the absence of cocaine 48 hours after their last pairing session in the test environment. For these tests, the Paired and Unpaired groups within each experiment were each subdivided into three groups $(N \sim 8 /$ grp $)$ that were equated with respect to the mean activity levels measured during the last four pairing sessions. One set of Paired and Unpaired groups then received bilateral infusions of artificial cerebrospinal fluid (aCSF; $0.5 \mu \mathrm{l} /$ side) into the region of interest, whereas the two other sets of groups received 0.1 or $0.2 \mathrm{nmol} / 0.5 \mu \mathrm{l} /$ side of a GABA receptor agonist.

The $\mathrm{GABA}_{\mathrm{A}}$ agonist muscimol was infused into the $\mathrm{mPFC}$, the $\mathrm{Bl}$, and the vSub, whereas the $\mathrm{GABA}_{\mathrm{B}}$ agonist baclofen was infused into the NAc. To perform these infusions, the obturators were removed and replaced with 28 gauge injector needles that extended 1 $\mathrm{mm}$ beyond the tip of the guide cannulae. These injectors were connected via plastic infusion tubing (PE-20) to $1 \mu \mathrm{l}$ microsyringes stationed on a metal frame $40 \mathrm{~cm}$ above a $28 \times 18 \times 12 \mathrm{~cm}$ Plexiglas chamber. Drug or aCSF solutions were administered manually over a 60 second period while the rats moved freely in the Plexiglas infusion chamber. The injectors were left in place for an additional 60 seconds to allow solutions to diffuse into the surrounding tissue, and they were then removed and replaced by the obturators. Approximately $15 \mathrm{~min}$ later, the rats were given i.p. injections of saline and placed into the activity chambers where locomotor activity was measured for 60 minutes in the absence of cocaine.

\section{Dose-Response Effects of Intra-NAc Baclofen and Intra-mPFC Muscimol on Locomotion}

Additional sets of rats were given tests for unconditioned locomotor activity after infusions of different doses of a GABA agonist into the NAc or mPFC. Each rat was given six or seven $60 \mathrm{~min}$ tests, with each test spaced $48 \mathrm{~h}$ apart. The rats were habituated to the chambers without receiving an infusion on the first two (NAc experiment) or three (mPFC experiment) occasions, and then tested after pretreatments with ascending doses of a GABA agonist on the subsequent four days. Rats with NAc cannulae received infusions of 

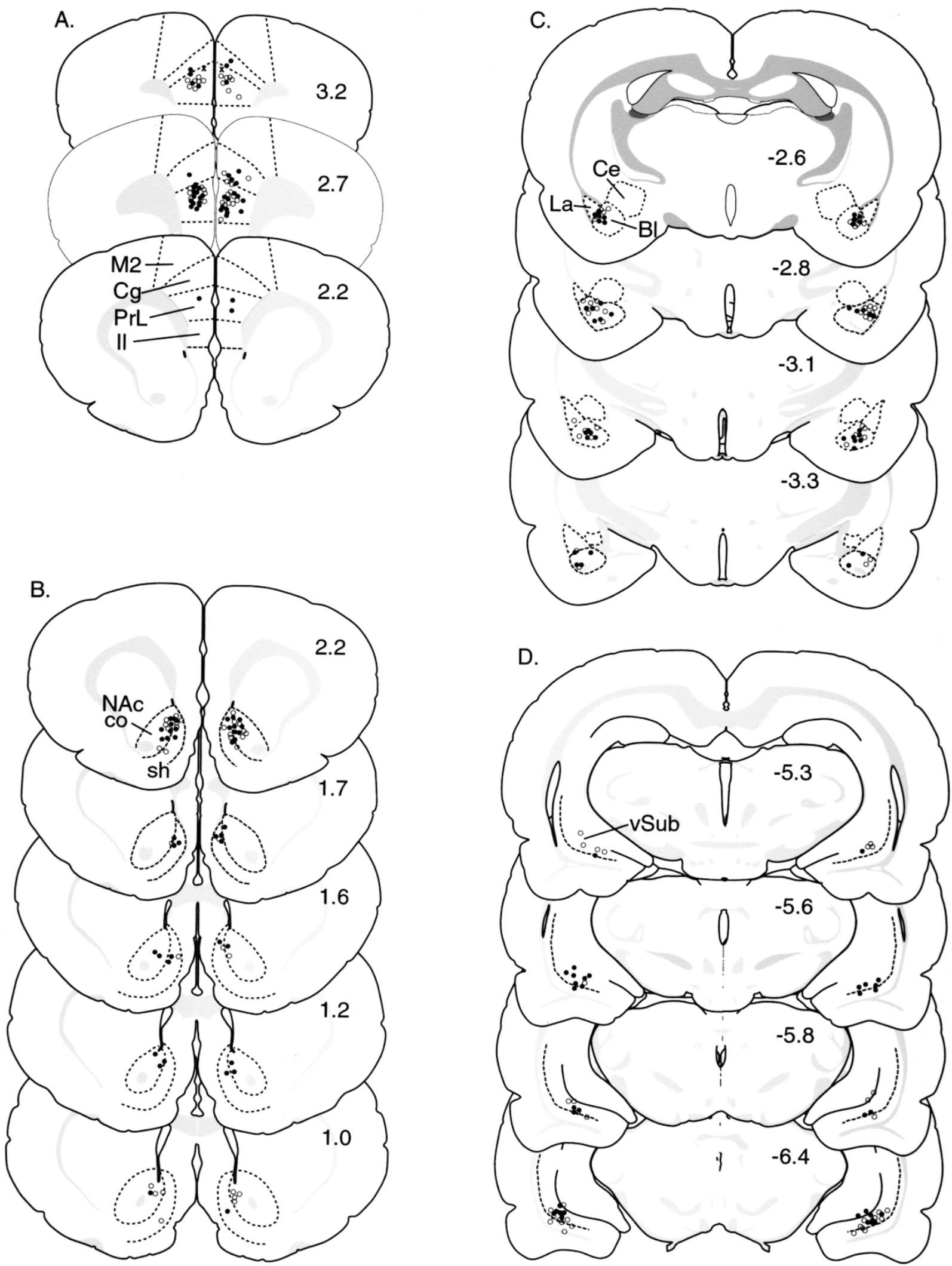

Figure 1. Representations of coronal sections of the rat brain illustrating the locations of the injector tips within the mPFC (A), the NAc (B), the Bl (C), and the vSub (D). Filled and open circles represent infusion sites in Paired and Unpaired rats, respectively. Brain representations were adapted from the Swanson Rat Brain Atlas graphics program (Swanson 1992). The numbers on each section represent the rostral-caudal coordinate relative to bregma as depicted in the rat brain atlas of Paxi- 
$0.05,0.1,0.2$, and $0.4 \mathrm{nmols} / 0.5 \mu \mathrm{l} /$ side of baclofen prior to the last four sessions, whereas rats with $\mathrm{mPFC}$ cannulae received $0.025,0.05,0.1$, and 0.2 nmols $/ 0.5$ $\mu \mathrm{l} /$ side of muscimol on these days. These infusions were performed using the procedures described above, and testing was conducted concurrently with the pairing phases for NAc- or mPFC-implanted rats in the abovementioned conditioning studies.

\section{Drugs}

Cocaine hydrochloride (NIDA Drug Supply, Research Triangle Park, NC) was dissolved in saline and injected i.p. in a volume of $1.0 \mathrm{ml} / \mathrm{kg}$. The $\mathrm{GABA}_{B}$ agonist, $\mathrm{R}(+)$-baclofen hydrochloride (Research Biochemicals Inc., Natick, MA) and the $\mathrm{GABA}_{\mathrm{A}}$ agonist, muscimol hydrobromide (Research Biochemicals Inc.) were dissolved in aCSF. The aCSF was prepared in the lab and consisted of $145 \mathrm{mM} \mathrm{Na}+, 2.7 \mathrm{mM} \mathrm{K}+, 1.2 \mathrm{mM} \mathrm{Ca}++$, $1.0 \mathrm{mM} \mathrm{Mg}++, 150 \mathrm{mM} \mathrm{Cl}-, 0.2 \mathrm{mM}$ ascorbate, $2 \mathrm{mM}$ $\mathrm{Na} 2 \mathrm{HPO} 4, \mathrm{pH} 7.4 \pm 0.1$.

\section{Statistical Analyses}

A one-way between, one-way within groups analysis of variance (ANOVA) was performed on locomotor activity counts measured during pairing sessions of each experiment to confirm the effectiveness of cocaine for inducing hyperactivity. Planned orthogonal comparisons were used to analyze differences in conditioning test activity observed between sets of Paired and Unpaired groups given the same dose of a GABA agonist within an experiment (see Hays (1981), for a description of this apriori statistical test). Planned orthogonal comparisons also were used to compare the unconditioned activity measured at each dose of intra-NAc baclofen or intra$\mathrm{mPFC}$ muscimol to that of Unpaired rats given sham injections on the same days. All differences were considered significant at $p<.05$.

\section{RESULTS}

The locations of injector tips for rats included in the data analyses are shown in Figures 1 and 2. Placements for the NAc, $\mathrm{mPFC}, \mathrm{Bl}$, and vSub were considered accurate if they were located within the structure of interest in both hemispheres. Behavioral data collected from animals with cannulae failing to meet these criteria were excluded from the analyses. Animals also were ex- cluded if histological analyses revealed evidence of severe infection at the injection site. Such animals had extensive damage to the tissue surrounding the cannulae, and re-examination of the experimental records typically revealed signs of physiological distress during the experiment that included a sudden weight loss (approximately $10 \%$ ) and concomitant change in behavioral activity. Overall, these exclusion criteria lead to removal of four rats from the NAc experiment, five from the $\mathrm{mPFC}$ experiment, nine from the $\mathrm{Bl}$ experiment, and seven from the vSub experiment. Rats were not excluded from the dorsal control experiments on the basis of injector placements, but five rats were removed from the mPFC dorsal control experiment due to extensive infection of cortical tissue. These exclusions resulted in final subject numbers of six to eight rats per group.

Analyses of the locomotor activity data from the pairing phase of each experiment confirmed that $\mathrm{CO}^{-}$ caine produced strong behavioral activating effects in all Paired groups examined. On average, test environment activity scores for cocaine-treated Paired rats were in the range of 5000 counts during each pairing session, whereas scores for saline-treated Unpaired rats were closer to 2400 counts (range of $F$ values for the groups factor in different experiments $=52.63$ to 83.16, with $p<$ .0001 in all cases).

The effects of intra-NAc infusions of baclofen or aCSF on the expression of conditioned hyperactivity are shown in Figure 3. Planned orthogonal comparisons conducted for each set of Paired and Unpaired rats revealed significant conditioned hyperactivity in Paired rats treated either with $\operatorname{aCSF}\left(\mathrm{F}_{1,32}=7.38, p<.01\right)$ or the low dose of baclofen $\left(0.1 \mathrm{nmols} / 0.5 \mu \mathrm{l} /\right.$ side; $\mathrm{F}_{1,32}=$ $7.13, p<.025)$. In contrast, there were no differences in the activity levels of Paired and Unpaired rats given intra-NAc infusions of the higher dose of baclofen $(0.2$ nmols $/ 0.5 \mu \mathrm{l} /$ side), suggesting that this treatment interfered with the expression of conditioned hyperactivity. Notably, this disruption of conditioned hyperactivity was characterized by an increase in the activity of Unpaired rats $\left(\mathrm{F}_{1,32}=7.96, p<.01\right.$ for aCSF vs. 0.2 nmols/side) rather than decreased locomotion in Paired rats ( $p>.85$ for aCSF vs. 0.2 nmols/side). It was not clear whether the disruptive effect of baclofen on conditioned hyperactivity was due to baclofen's actions in the shell subregion of the NAc or from actions within the core, as the injection sites were clustered around the border between these two subterritories (see Figure 1).

The activity levels of rats given infusions of muscimol or aCSF into the prelimbic/cingulate regions of the

nos and Watson (1998). Abbreviations: Bl, basolateral nucleus of the amygdala; Ce, central nucleus of the amygdala; $\mathrm{Cg}$, cingulate cortex; co, NAc core; Il, infralimbic cortex; La, lateral nucleus of the amygdala; M2, secondary motor cortex; PrL, prelimbic cortex; sh, NAc shell; vSub, ventral subiculum. 
A.

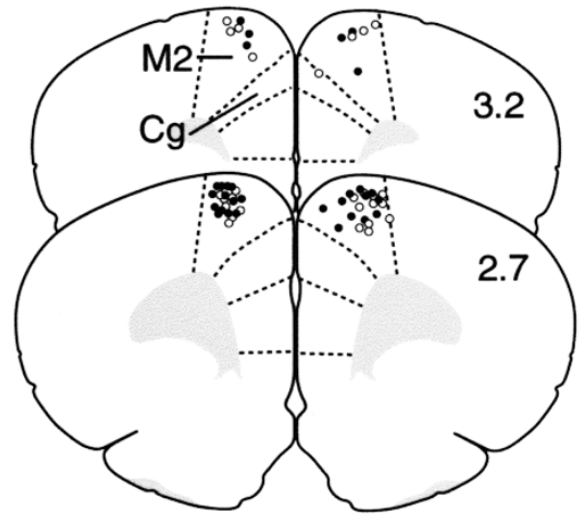

B.

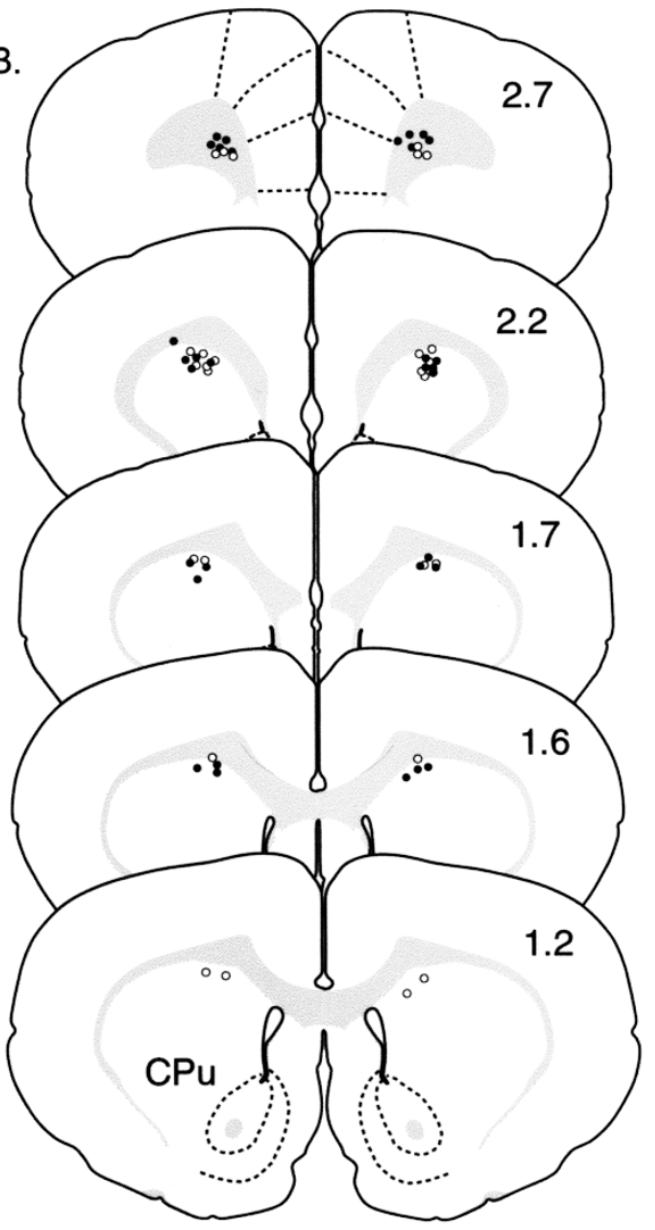

C.

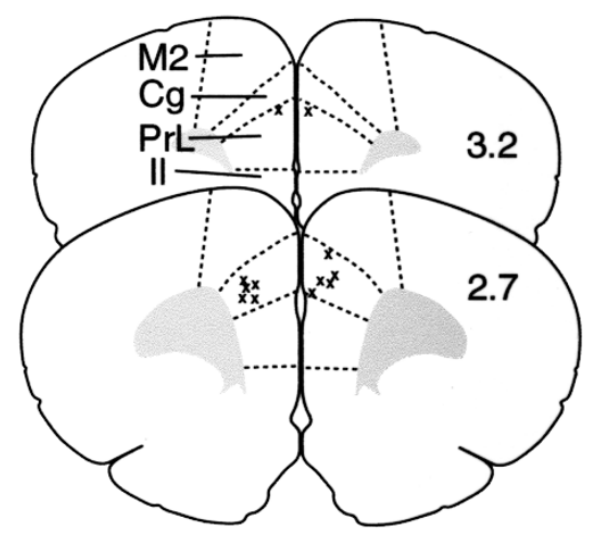

D.

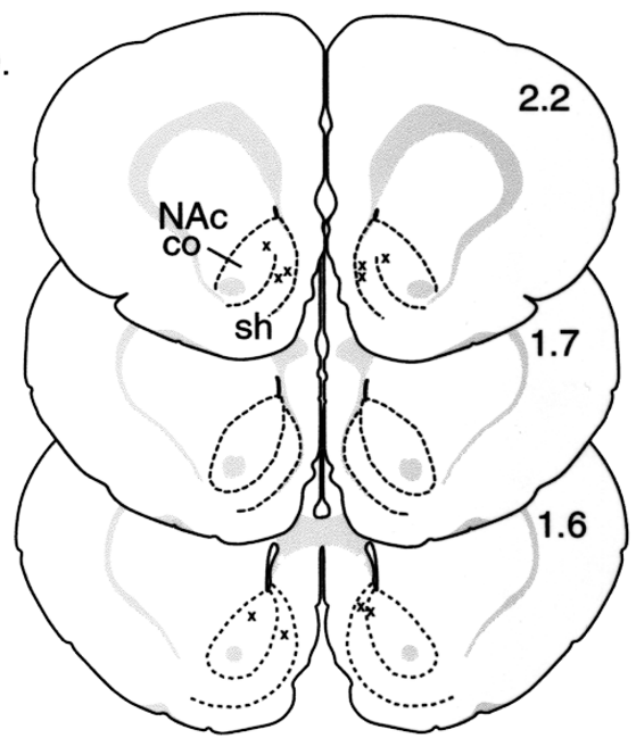

Figure 2. Representations of coronal sections of the rat brain illustrating the locations of the injector tips for: (A) rats receiving muscimol into sites dorsal to the MPFC; (B) rats receiving baclofen into sites dorsal to the NAc; (C) rats tested with different doses of muscimol infused into the mPFC; and (D) rats tested with different doses of baclofen infused into the NAc. Infusion sites are represented by filled circles in Paired rats, open circles in Unpaired rats, and Xs in rats used for doseresponse experiments. The numbers on each section represent the rostral-caudal coordinate relative to bregma as depicted in the rat brain atlas of Paxinos and Watson (1998). Abbreviations: Cg, cingulate cortex; co, NAc core; CPu, caudate putamen; Il, infralimbic cortex; M2, secondary motor cortex; PrL, prelimbic cortex; sh, NAc shell. 


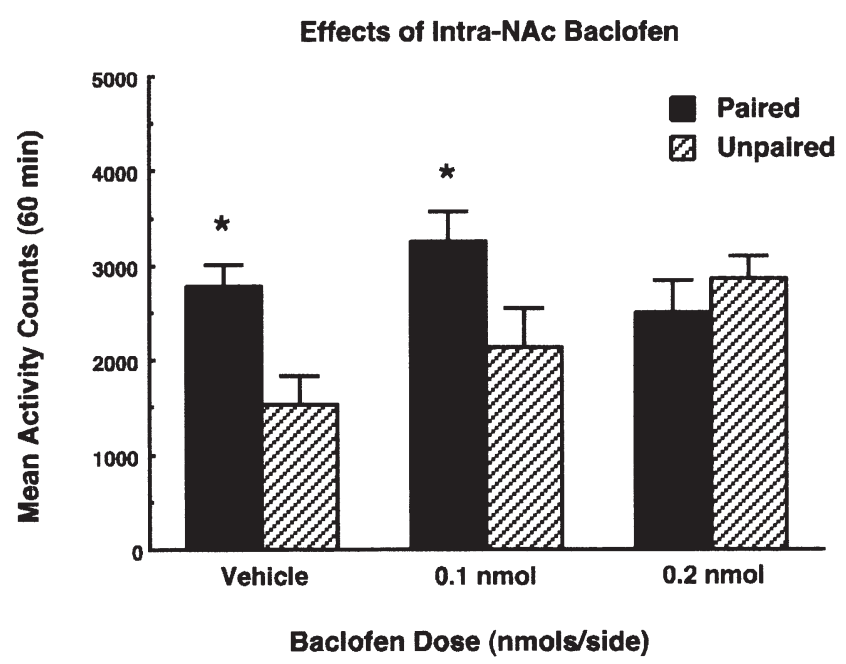

Figure 3. Locomotor activity counts recorded during the 60-min test for conditioned hyperactivity in Paired and Unpaired rats pretreated with vehicle, 0.1 , or 0.2 nmols $/ 0.5$ $\mu \mathrm{l} /$ side of baclofen into the NAc. Conditioned hyperactivity was evident in Paired rats given vehicle or $0.1 \mathrm{nmol} / \mathrm{side}$ baclofen, but this conditioned response was disrupted by 0.2 $\mathrm{nmol} /$ side baclofen. Asterisks indicate significant differences between Paired and Unpaired groups at $p<.05$.

mPFC prior to the test for conditioned hyperactivity are shown in Figure 4. Planned orthogonal comparisons revealed that Paired rats were more active than Unpaired rats following infusions of aCSF into the $\operatorname{mPFC}\left(\mathrm{F}_{1,37}=\right.$ $6.40, p<.025)$, but not following infusions of either 0.1 or $0.2 \mathrm{nmols} / 0.5 \mu \mathrm{l} /$ side muscimol. Thus, muscimol in-

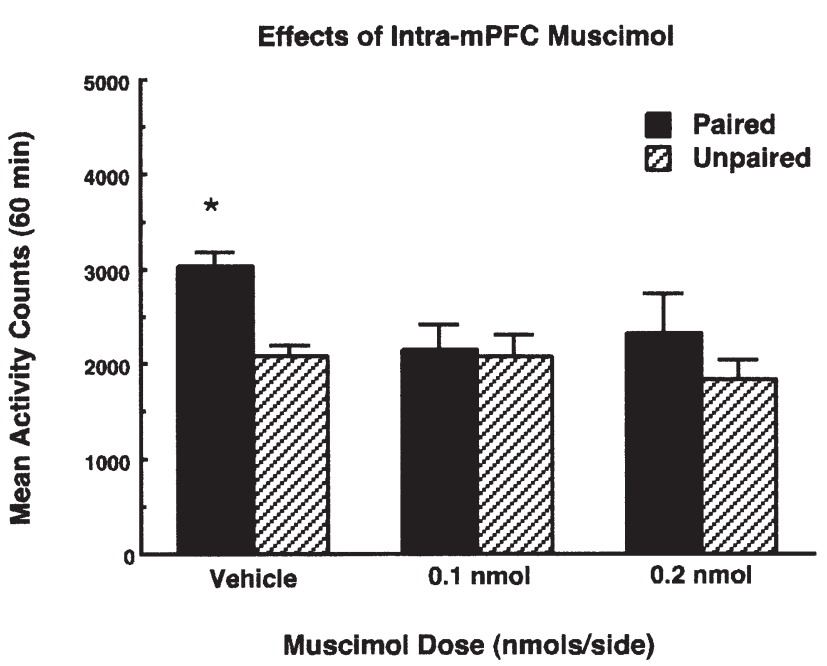

Figure 4. Locomotor activity counts recorded during the test for conditioning in Paired and Unpaired rats pretreated with vehicle, 0.1 , or 0.2 nmols $/ 0.5 \mu \mathrm{l} /$ side muscimol into the mPFC. Both 0.1 and 0.2 nmols $/ 0.5 \mu \mathrm{l} /$ side muscimol blocked the expression of conditioned hyperactivity in Paired rats. The asterisk indicates significant differences between Paired and Unpaired groups at $p<.05$. fusions into the mPFC blocked the expression of conditioned hyperactivity.

In contrast to the effects obtained with $\mathrm{mPFC}$ infusions, muscimol did not alter conditioned hyperactivity when infused into the Bl or vSub (see Figures 5 and 6). Paired rats were significantly more active than Unpaired animals regardless of the treatment administered into each region (range of $\mathrm{F}$ values for $\mathrm{Bl}$ groups: $\mathrm{F}_{1,33}=9.33$ to 23.55, $p<.005$; range of $\mathrm{F}$ values for $\mathrm{vSub}$ groups: $\mathrm{F}_{1,35}=5.31$ to $\left.7.86, p<.05\right)$. Notably, the higher dose of muscimol produced a substantial reduction in the activity of Unpaired rats when infused into the Bl $\left(\mathrm{F}_{1,35}=3.65, p=.06\right)$, suggesting that such infusions were effective in reducing unconditioned locomotor activity.

Additional experiments revealed that the expression of conditioned hyperactivity also was not affected by infusion of $0.2 \mathrm{nmols} / 0.5 \mu \mathrm{l} /$ side baclofen into sites 3.0 $\mathrm{mm}$ dorsal to the NAc (Figure 7a). The differences between Paired and Unpaired groups were significant for rats pretreated with either aCSF $\left(\mathrm{F}_{1,28}=8.46, p<.01\right)$ or baclofen $\left(\mathrm{F}_{1,28}=11.04, p<.005\right)$. Thus, the effects of baclofen observed with intra-NAc infusions could not be attributed to diffusion of the compound up the external surface of the guide cannulae and action within the dorsal striatum. Likewise, the blockade of conditioning produced by intra-PFC muscimol did not appear to be due to actions at dorsal sites within the secondary motor cortex (Figure $7 \mathrm{~b}$ ). Infusion of 0.2 nmols $/ 0.5 \mu \mathrm{l} /$ side

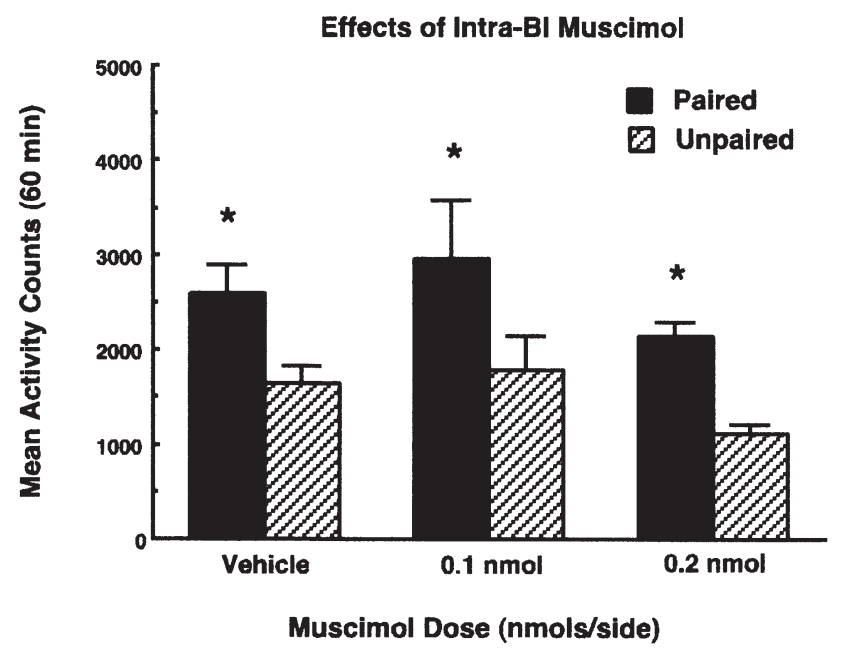

Figure 5. Locomotor activity counts recorded during the test for conditioning in Paired and Unpaired rats pretreated with vehicle, 0.1 , or $0.2 \mathrm{nmols} / 0.5 \mu \mathrm{l} /$ side muscimol into the Bl. Muscimol infusions into this region had no effect on the expression of conditioned hyperactivity in Paired rats. Note that conditioned hyperactivity was still evident after infusions of the higher dose of muscimol despite an overall reduction in activity in both Paired and Unpaired groups. Asterisks indicate significant differences between Paired and Unpaired groups at $p<.05$. 
Effects of Intra-vSub Muscimol

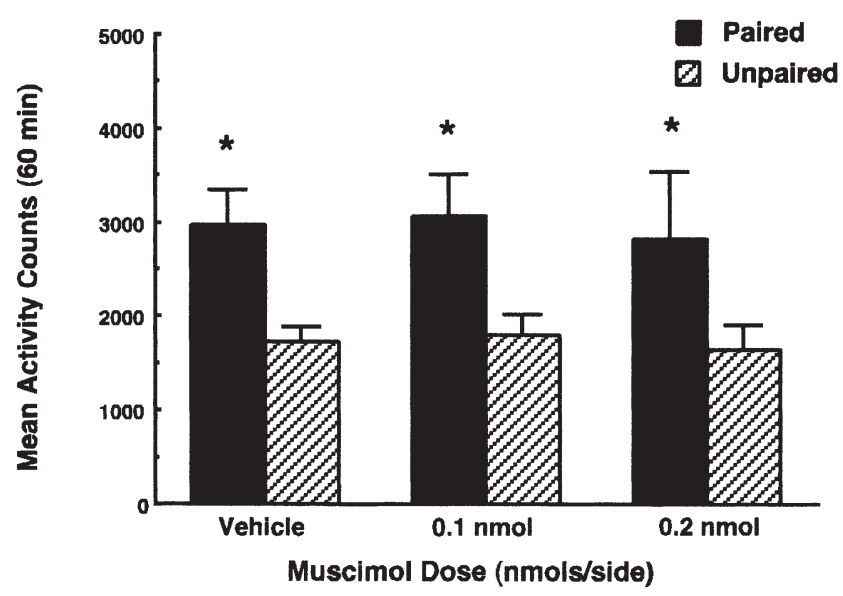

Figure 6. Locomotor activity counts recorded during the test for conditioning in Paired and Unpaired rats pretreated with vehicle, 0.1 , or $0.2 \mathrm{nmols} / 0.5 \mu \mathrm{l} /$ side muscimol into the vSub. Conditioned hyperactivity was not affected by either dose of muscimol in this region. Asterisks indicate significant differences between Paired and Unpaired groups at $p<.05$.

muscimol into this region resulted in only a moderate attenuation of conditioned hyperactivity such that the differences between Paired and Unpaired groups narrowly missed statistical significance $\left(\mathrm{F}_{1,22}=3.68, p=\right.$ .068 vs. $F_{1,22}=5.85, p<.025$ for aCSF pretreated groups). In fact, further analyses indicated that the muscimol-pretreated Paired rats were significantly more active than similarly treated Unpaired rats during the first half-hour of testing $\left(\mathrm{F}_{1,22}=5.69, p<.05\right)$, and these group differences disappeared only in the second half-hour when the drug might have had the opportunity to diffuse to nearby sites in the MPFC.

The effects of infusing different doses of baclofen into the NAc, or muscimol into the $\mathrm{mPFC}$, on unconditioned locomotor activity are shown in Figure 8. Comparisons of the activity of baclofen-treated rats with that of Unpaired rats given sham infusions on the same days revealed evidence of significantly increased locomotion after intra-NAc infusions of 0.2 and 0.4 nmols/ $0.5 \mu \mathrm{l} /$ side baclofen $\left(\mathrm{F}_{1,35}=6.24, p<.025\right.$ and $\mathrm{F}_{1,35}=$ 11.27, $p<.0025$, respectively). This finding indicated that the increased activity produced by $0.2 \mathrm{nmols} / 0.5$ $\mu \mathrm{l} /$ side baclofen during conditioning tests represented an unconditioned behavioral activating effect of $\mathrm{GABA}_{\mathrm{B}}$ receptor stimulation within the NAc. Analyses of activity levels measured after muscimol infusions into the $\mathrm{MPFC}$ revealed that locomotion was significantly reduced relative to sham-infused Unpaired rats at the lowest dose tested $\left(\mathrm{F}_{1,48}=9.52, p<.005\right)$, but this effect was not evident at higher doses. Notably, activity levels in both agonist- and sham-infused rats declined over the course of repeated testing due to progressive habituation to the test environment. Although this habituation would be a significant confounding factor in a within-subject analysis of dose-response effects, it poses less of a problem for between-groups comparisons of activity scores measured concurrently in agonist- and sham-infused rats with identical habituation histories.
A. Infusions Dorsal to the NAC

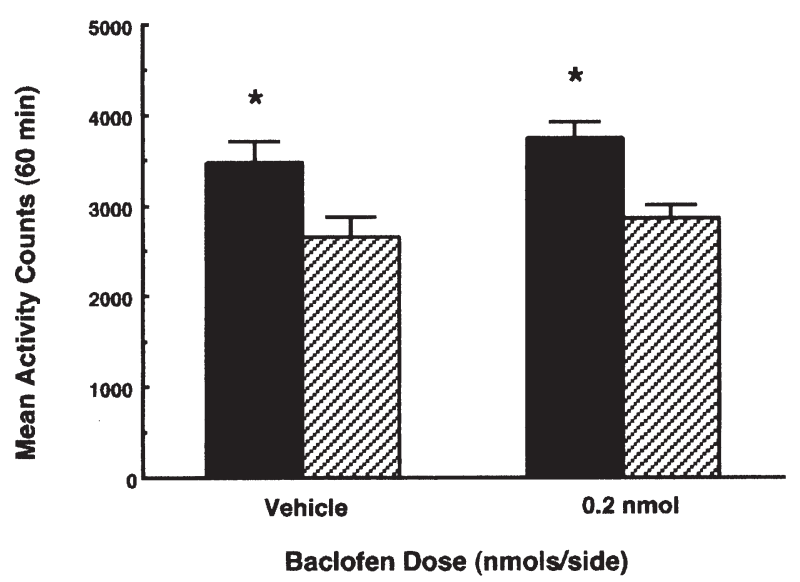

B. Infusions Dorsal to the MPFC

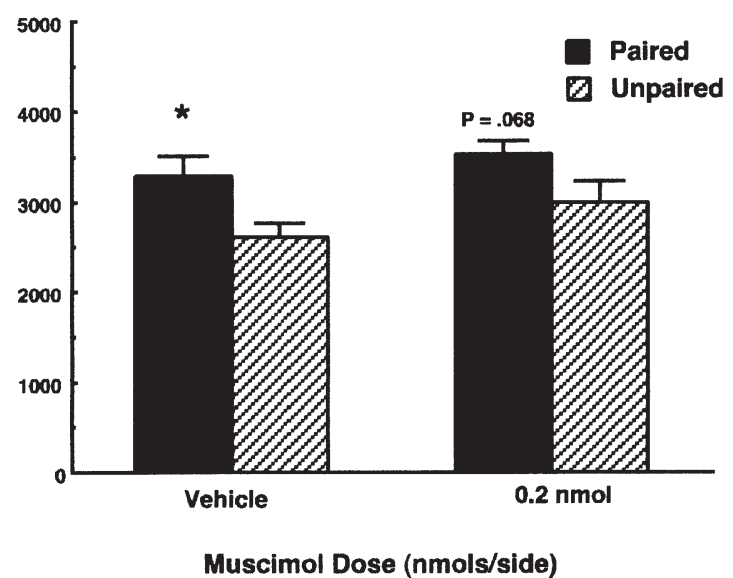

Figure 7. Locomotor activity counts recorded during the test for conditioning in Paired and Unpaired rats pretreated with: (A) vehicle or $0.2 \mathrm{nmols} / 0.5 \mu \mathrm{l} / \mathrm{side}$ baclofen into control regions dorsal to the NAc; or (B) vehicle or $0.2 \mathrm{nmols} / 0.5 \mu \mathrm{l} / \mathrm{side}$ muscimol into control regions dorsal to the mPFC. Baclofen infusions into control sites dorsal to the NAc had no effect on conditioned hyperactivity. Muscimol only slightly attenuated conditioned hyperactivity when it was infused into secondary motor regions (M2) dorsal to the mPFC. Further analysis indicated that this attenuation occurred only late in the session when muscimol might have had time to diffuse to sites within the cingulate or prelimbic cortex (see text). Asterisks indicate significant differences between Paired and Unpaired groups at $p<.05$. 

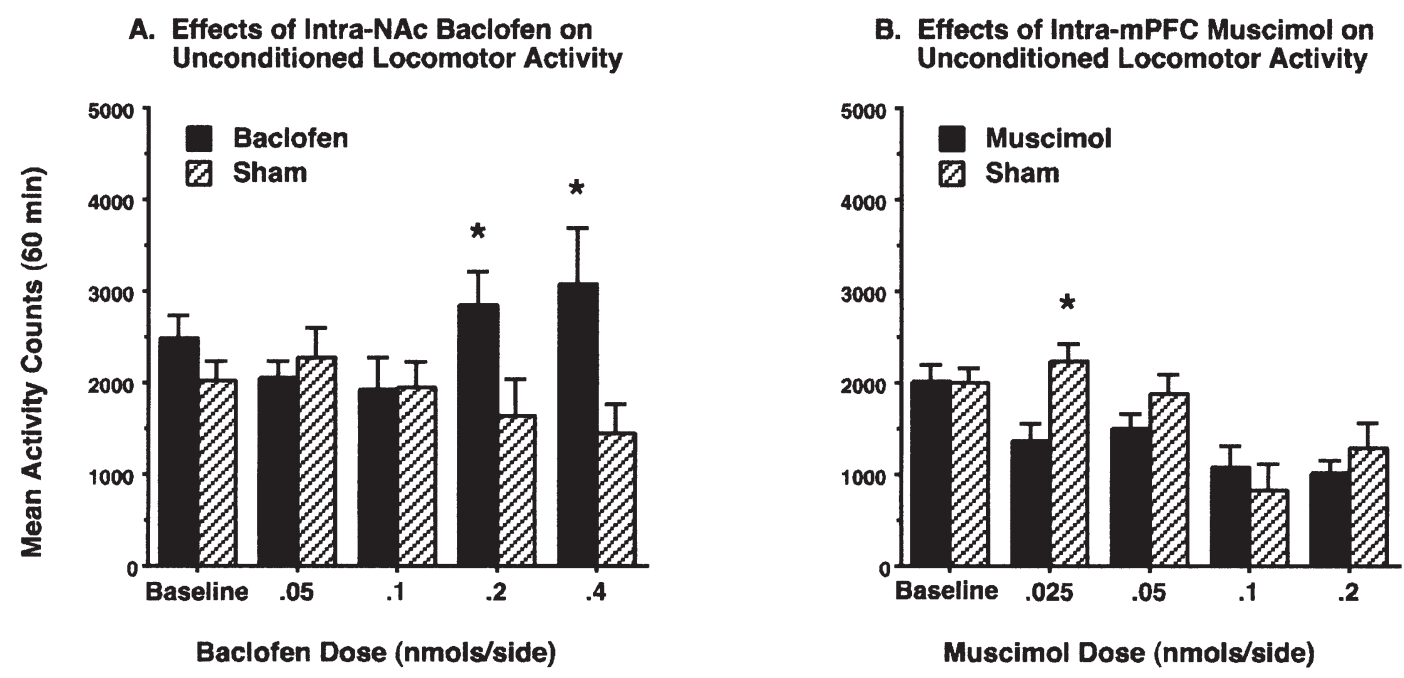

Figure 8. Effects of infusing different doses of baclofen into the NAc or muscimol into the mPFC on unconditioned locomotor activity. The solid bars represent the activity levels measured in unconditioned rats during an initial baseline session, and following treatments with different doses of a GABA agonist using a within subjects design. The dose-response study for each brain area was run concurrently with the pairing phases of the respective conditioning experiments, so that activity levels at each agonist dose could be compared with the activity levels of sham-infused Unpaired rats (hatched bars) tested on the same treatment days. (A) Intra-NAc baclofen infusions increased unconditioned locomotor activity at the two highest doses examined $(0.2$ and $0.4 \mathrm{nmols} / 0.5 \mu \mathrm{l} / \mathrm{side})$. (B) Intra-mPFC muscimol infusions decreased unconditioned locomotor activity at the lowest dose $(0.025 \mathrm{nmols} / 0.5 \mu \mathrm{l} /$ side $)$, but this effect was not evident at higher doses. Note that the decline in mean activity levels observed across tests in each experiment is likely due to habituation to the test environment over the course of repeated testing. Asterisks indicate significant differences between agonist-treated and sham-infused rats at $p<.05$.

\section{DISCUSSION}

This study examined the effects of pharmacologically inhibiting the NAc, mPFC, Bl, or vSub on the expression of Pavlovian conditioned hyperactivity responses to a cocaine-associated environment. The findings indicated that conditioned hyperactivity responses could be disrupted by infusions of a GABA agonist into the NAc or the $\mathrm{mPFC}$, but not by similar infusions into the $\mathrm{Bl}$, the vSub, or control sites dorsal to the NAc. Although there was a moderate attenuation of conditioned hyperactivity following control infusions of muscimol into the secondary motor cortex, this effect occurred late in the test session and may have been due to diffusion of the drug to the nearby cingulate region of the mPFC.

The disruption of conditioned hyperactivity produced by intra-NAc infusions of baclofen was characterized by increased activity levels in the baclofen-pretreated Unpaired group during the conditioning test rather than reduced activity in Paired rats (compare 0.2 nmols/side vs. vehicle treated groups in Figure 3). This unusual pattern of results raises questions as to whether the expression of conditioned locomotor responses were truly inhibited, or whether conditioned activity was masked non-specifically by unconditioned behavioral activating effects of the $0.2 \mathrm{nmols} /$ side dose of baclofen. Although the latter possibility is a reasonable concern, there is good reason to believe that the re- sults obtained with intra-NAc baclofen infusions reflected more than just a masking of conditioned activity. Numerous studies have shown that unconditioned stimulant effects of drugs are normally additive with conditioned activating properties of the test environment. For example, psychomotor stimulants, opiates, and NMDA receptor antagonists have all been found to increase locomotor activity equally in both Paired and Unpaired groups so that the conditioned component of the locomotor response is preserved (Cervo and Samanin 1996; Druhan and Wilent 1999; Kalivas and Stewart 1991). The absence of such additivity in Paired rats within the present experiments suggests that intra-NAc baclofen blocked the expression of conditioned hyperactivity in addition to stimulating unconditioned locomotion. In fact, baclofen may have acted directly on processes responsible for initiating behavioral activity in a manner that superseded the control exerted by conditioned stimuli. This interpretation would be consistent with a substantial body of evidence implicating the NAc in the expression of both conditioned and unconditioned locomotor responses (DiCiano et al. 1998a,b; Gold et al. 1988; Gratton and Wise 1994; Kelly and Iverson 1976; Kiyatkin and Stein 1996; Layer et al. 1993; Neisewander et al. 2000; Pijnenburg et al. 1975).

Infusions of muscimol into a region of the mPFC spanning the prelimbic and cingulate cortex prevented 
conditioned hyperactivity in Paired rats at doses that did not affect locomotion in Unpaired animals. This finding adds to a growing body of evidence implicating the $\mathrm{mPFC}$ in Pavlovian conditioning processes. For example, studies employing traditional Pavlovian conditioning paradigms have shown that aversively conditioned stimuli can evoke learning-related changes in neuronal activity within prelimbic and cingulate areas of the mPFC (Maxwell et al. 1994; Peterson 1986; Powell et al. 1996), and increase dopamine and serotonin efflux in these regions (Wedzony et al. 1996; Yoshioka et al. 1995, 1996). Lesions of the mPFC also can disrupt Pavlovian conditioned responses to sucrose or foot-shock related stimuli (Bussey et al. 1997; McLaughlin and Powell 1999; Powell et al. 1994). Studies of conditioned drug effects have further shown that cocaine-related stimuli can increase serotonin efflux and stimulate the expression of Fos-related proteins within the mPFC in rats (Brown and Fibiger 1992; Carey and Damianopoulos 1994; Franklin and Druhan 2000; Neisewander et al. 2000), whereas lesions of this region interfere with the development of conditioned preferences for a cocaineassociated environment and with the expression of cocaine-induced sensitization effects that depend heavily on contextual conditioning (Isaac et al. 1989; Pierce et al. 1998; Tzschentke and Schmidt 1998). In humans, neural imaging studies have provided evidence for increased blood flow in the cingulate cortex of cocaine addicts during presentations of cocaine-related stimuli (Childress et al. 1999; Maas et al. 1998; although see Grant et al. 1996). These latter drug studies indicate that mPFC regions are important for Pavlovian conditioned responses to stimuli associated with cocaine administration. Interestingly, recent disconnection experiments suggest that the cingulate cortex and the NAc may be components of a common neural circuitry controlling Pavlovian conditioned approach responses to appetitive conditioned stimuli (Everitt et al. 1999). Likewise, the mPFC and NAc regions examined in the present study may interact directly or indirectly to control Pavlovian conditioned locomotor responses to cocaine-related stimuli.

It may seem surprising that muscimol infusions into the $\mathrm{Bl}$ or vSub failed to affect conditioned hyperactivity given the substantial evidence that these structures are important for learned responses to stimuli associated with both drug and natural reinforcers (Burns et al. 1993; Everitt et al. 1991, 1999; Hitchcott and Phillips 1997; Ono et al. 1995; Whitelaw et al. 1996). However, the findings obtained with $\mathrm{Bl}$ infusions concur with previous evidence that the expression of conditioned hyperactivity is not affected by excitotoxin lesions of this region (Ahmed et al. 1995; Brown and Fibiger 1993). Moreover, the overall pattern of results obtained in this study corresponds well with several lines of evidence indicating a preferential involvement of the
mPFC and NAc in regulating Pavlovian conditioned responses to drug- or food-related stimuli. As mentioned above, immunohistochemical mapping studies in our laboratory have shown that conditioned hyperactivity in a cocaine-associated environment is accompanied by conditioned increases in Fos-related protein expression within the NAc and mPFC. In contrast, context-dependent increases in Fos-related proteins were not observed within the $\mathrm{Bl}$ or vSub (Franklin and Druhan 2000). In lesion experiments, destruction of terminals or cells within the NAc or dorsal mPFC blocked the expression of sensitization to the behavioral activating effects of cocaine, a phenomenon which is highly regulated by Pavlovian conditioned associations between the drug and injection context (Pert et al. 1990), whereas lesions of the $\mathrm{Bl}$ or the hippocampal efferents within the fornix/fimbria had no effect (Pierce et al. 1998). Likewise, studies involving more traditional incentives revealed that Pavlovian conditioned approach responses to food-related stimuli could be prevented by neurotoxic lesions of the NAc or cingulate cortex, but not by lesions of the Bl or vSub (Bussey et al. 1997; Everitt et al. 1999). These studies suggest that the NAc and mPFC are critically involved in the expression of simple Pavlovian conditioned responses to drug- and food-related stimuli, whereas the $\mathrm{Bl}$ and vSub may be less important for this form of learned response (see Everitt et al. 1999). The Bl and vSub may become more important for controlling behavior as task demands and the complexity of environmental contingencies increase.

Stimuli associated with cocaine use can elicit potent cravings that may sustain drug use and promote relapse in long-term users (Childress et al. 1992; Newlin 1992; O'Brien et al. 1992). A component of this craving response may stem from the conditioned behavioral arousal elicited by cocaine-associated stimuli. If so, then compounds that inhibit NAc and mPFC processes involved in this conditioned arousal may be useful for treating drug abuse. In fact, the present findings that GABA agonist infusions into either the NAc or mPFC can interfere with the expression of conditioned hyperactivity indicate that GABA agonists might be useful as a treatment for inhibiting craving-related responses to cocaine-associated stimuli in humans. The exploration of such GABA-ergic mechanisms for conditioned cravings represents an important avenue for future research.

\section{ACKNOWLEDGMENTS}

This work was supported by National Institute on Drug Abuse grant number DA08381 to JPD. and fellowship number DA05878 to TRF. The authors gratefully acknowledge the technical assistance provided by Carrie Walters and Kimberly Altomare. Cocaine was donated by the National Institute on Drug Abuse. 


\section{REFERENCES}

Ahmed SH, Cador M, Le Moal M, Stinus L (1995): Amphetamine-induced conditioned activity in rats: comparison with novelty-induced activity and role of the basolateral amygdala. Behav Neurosci 109:723-733

Barr GA, Sharpless NS, Cooper S, Schiff SR, Paredes W, Bridger WH (1983): Classical conditioning, decay and extinction of cocaine-induced hyperactivity and stereotypy. Life Sci 33:1341-1351

Bowman EM, Aigner TG, Richmond BJ (1996): Neural signals in the monkey ventral striatum related to motivation for juice and cocaine rewards. J Neurophysiol 75:1061-1073

Brown EE, Fibiger H (1993): Differential effects of excitotoxic lesions of the amygdala on cocaine-induced conditioned locomotion and conditioned place preference. Psychopharmacology 113:123-130

Brown EE, Fibiger HC (1992): Cocaine-induced conditioned locomotion: Absence of associated increases in dopamine release. Neuroscience 48:621-629

Burns LH, Robbins TW, Everitt BJ (1993): Differential effects of excitotoxic lesions of the basolateral amygdala, ventral subiculum, and medial prefrontal cortex on responding with conditioned reinforcement and locomotor activity potentiated by intra-accumbens infusions of d-amphetamine. Behav Brain Res 55:167-183

Bussey TJ, Everitt BJ, Robbins TW (1997): Dissociable effects of cingulate and medial frontal cortex lesions on stimulus-reward learning using a pavlovian autoshaping procedure for the rat: Implications for the neurobiology of emotion. Behav Neurosci 111:908-919

Carey RJ, Damianopoulos EN (1994): Conditioned cocaine induced hyperactivity: An association with increased medial prefrontal cortex serotonin. Behav Brain Res 62:177-185

Cervo L, Samanin R (1996): Effects of dopaminergic and glutamatergic antagonists on the establishment and expression of conditioned locomotion to cocaine in rats. Brain Res 731:31-38

Childress AR, Ehrman RN, Rohsenow D, Robbins SJ, O'Brien CP (1992): Classically conditioned factors in drug dependence. In Lowinson J, Ruiz P, Millman RB (eds), Substance Abuse: A Comprehensive Textbook. Baltimore, MD, Williams and Wilkens, pp 56-69

Childress AR, Mozley PD, McElgin W, Fitzgerald BA, Reivich M, O'Brien CP (1999): Limbic activation during cueinduced cocaine craving. Am J Psychiatry156:11-18

DiCiano P, Blaha CD, Phillips AG (1998a): The relation between dopamine oxidation currents in the nucleus accumbens and conditioned increases in motor activity in rats following repeated administration of d-amphetamine or cocaine. Eur J Neurosci 10:1113-1120

DiCiano P, Blaha CD, Phillips AG (1998b): Conditioned changes in dopamine oxidation currents in the nucleus accumbens of rats by stimuli paired with self-administration or yoked-administration of d-amphetamine. Eur J Neurosci 10:1121-1127

Druhan JP, Wilent WB (1999): Effects of the competitive NMDA receptor antagonist, CPP, on the development and expression of conditioned hyperactivity and sensi- tization induced by cocaine. Behav Brain Res 102: 195-210

Everitt BJ, Morris KA, O’Brien A, Robbins TW (1991): The basolateral amygdala-ventral striatal system and conditioned place preference: Further evidence of limbic striatal interactions underlying reward-related processes. Neuroscience 42:1-18

Everitt BJ, Parkinson JA, Olmstead MC, Arroya M, Robledo P, Robbins TW (1999): Associative processes in addiction and reward: The role of amygdala-ventral striatal subsystems. Ann N Y Acad Sci 877:486-498

Fontana DJ, Post RM, Pert A (1993): Conditioned increases in mesolimbic dopamine overflow by stimuli associated with cocaine. Brain Res 629:31-39

Franklin TR, Druhan J (2000): Expression of fos-related antigens in the nucleus accumbens and associated regions following exposure to a cocaine-paired environment. Eur J Neurosci 12:2097-2106

Giampoala MM, Uzwiak AJ, Fabbricatore AT, West MO, Peoples LL (1999): Firing patterns of accumbal neurons during cue- and drug-induced reinstatement of cocaine seeking in the rat. Soc Neurosci Abstr 25:560

Gold LH, Swerdlow NR, Koob GF (1988): The role of mesolimbic dopamine in conditioned locomotion produced by amphetamine. Behav Neurosci 102:544-552

Grant S, London ED, Newlin, DB, Villemagne VL, Liu X (1996): Activation of memory circuits during cueinduced craving. Proc Natl Acad Sci U S A 93:1204012045

Gratton A, Wise RA (1994): Drug- and behavior-associated changes in dopamine-related electrochemical signals during intravenous cocaine self-administration in rats. J Neurosci 14:4130-4146

Hays WL (1981): Statistics. New York, CBS College Publishing

Hiroi N, White NM (1991): The lateral nucleus of the amydala mediates the expression of the amphetamine-produced conditioned place preference. J Neurosci 11: 2107-2116

Hitchcott PK, Phillips GD (1997): Amygdala and hippocampus control dissociable aspects of drug-associated conditioned rewards. Psychopharmacology 131:187-195

Hitchcott PK, Phillips GD (1998): Double dissociation of the behavioural effects of $\mathrm{R}(+)$ 7-OH-DPAT infusions in the central and basolateral amygdala nuclei upon Pavlovian and instrumental conditioned appetitive behaviours. Psychopharmacology 140:458-469

Isaac WL, Nonneman AJ, Neisewander J, Landers T, Bardo MT (1989): Prefrontal cortex lesions differentially disrupt cocaine-reinforced conditioned place preference but not conditioned taste aversion. Behav Neurosci 103:345-355

Izquierdo I, Quillfeldt JA, Zanatta MS, Quevedo J, Schaeffer E, Schmitz PK, Medina JH (1997): Sequential role of hippocampus and amygdala, entorhinal cortex and parietal cortex in formation and retrieval of memory for inhibitory avoidance in rats. Eur J Neurosci 9:786-793

Kalivas PW, Stewart J (1991): Dopamine transmission in the initiation and expression of drug- and stress-induced sensitization of motor activity. Brain Res Rev 16:233-244

Kelly PH, Iverson SD (1976): Selective 6-OHDA-induced 
destruction of mesolimbic dopamine neurons: Abolition of psychostimulant induced locomotor activity in rats. Eur J Pharmacol 40:45-56

Kiyatkin EA, Stein EA (1996): Conditioned changes in nucleus accumbens dopamine signal established by intravenous cocaine in rats. Neurosci Lett 211:73-76

Layer RT, Uretsky NJ, Wallace LJ (1993): Effects of the AMPA/kainate receptor antagonist DNQX in the nucleus accumbens on drug-induced conditioned place preference. Brain Res 617:267-273

Maas LC, Lukas SE, Kaufman MJ, Weiss RD, Daniels SL, Rogers VW, Kukes TJ, Renshaw PF (1998): Functional magnetic resonance imaging of human brain activation during cue-induced cocaine craving. Am J Psychiatry 155:124-126

Martin JH (1991): Autoradiographic estimation of the extent of reversible inactivation produced by microinjection of lidocaine and muscimol in the rat. Neurosci Lett 127:160-164

Maxwell B, Powell DA, Buchanan SL (1994): Multiple- and single-unit activity in area 32 (prelimbic region) of the medial prefrontal cortex during Pavlovian heart rate conditioning in rabbits. Cereb Cortex 4:230-246

McLaughlin J, Powell DA (1999): Pavlovian heart rate and jaw movement conditioning in the rabbit: Effects of medial prefrontal lesions. Neurobiol Learn Mem 71:150-166

Muller J, Corodimas KP, Fridel Z, Ledoux JE (1997): Functional inactivation of the lateral and basal nuclei of the amygdala by muscimol infusion prevents fear conditioning to an explicit conditioned stimulus and to contextual stimuli. Behav Neurosci 111:683-691

Neisewander JL, Baker DA, Fuchs RA, Tran-Nguyen LT, Palmer A, Marshall JF (2000): Fos protein expression and cocaine-seeking behavior in rats after exposure to a cocaine self-administration environment. J Neurosci 20:798-805

Newlin DB (1992): A comparison of drug conditioning and craving for alcohol and cocaine. Recent Dev Alcohol 10:147-164

O'Brien CP, Childress AR, McLellan AT, Ehrman R (1992): Classical conditioning in drug-dependent humans. Ann N Y Acad Sci 654:400-415

Ono T, Nishijo H, Uwano T (1995): Amygdala role in conditioned associative learning. Prog Neurobiol 46:401-422

Paxinos G, Watson C (1998): The Rat Brain in Stereotaxic Coordinates. San Diego, Academic Press

Pert A (1994): Neurobiological mechanisms underlying the acquisition and expression of incentive motivation by cocaine-associated stimuli: relationship to craving. NIDA Res Monogr 145:163-190

Pert A, Post RM, Weiss SRB (1990): Conditioning as a critical determinant of sensitization induced by psychomotor stimulants. NIDA Res Monogr 97:208-241

Peterson SL (1986): Prefrontal cortex neuron activity during a discriminative conditioning paradigm in unanesthetized rats. Int J Neurosci 29:245-254

Pierce RC, Reeder DC, Hicks J, Morgan ZR, Kalivas PW (1998): Ibotenic acid lesions of the dorsal prefrontal cortex disrupt the expression of behavioral sensitization to cocaine. Neuroscience 82:1103-1114

Pijnenburg AJJ, Honig WMM, Van Rossum JM (1975): Inhibition of $\mathrm{d}$-amphetamine-induced locomotor activity by injection of haloperidol into the nucleus accumbens of the rat. Psychopharmacologia 41:87-95

Powell DA, Maxwell B, Penney J (1996): Neuronal activity in the medial prefrontal cortex during Pavlovian eyeblink and nictitating membrane conditioning. J Neurosci 16:6296-6306

Powell DA, Watson K, Maxwell B (1994): Involvement of subdivisions of the medial prefrontal cortex in learned cardiac adjustments in rabbits. Behav Neurosci 108:294-307

Shi WX, Rayport S (1994): GABA synapses formed in vitro by local axon collaterals of nucleus accumbens neurons. J Neurosci 14:4548-4560

Stewart J, de Wit H, Eikelboom R (1984): Role of unconditioned and conditioned drug effects in the self-administration of opiates and stimulants. Psychol Rev 91:251-268

Swanson LW (1992): Brain Maps: Structure of the Rat Brain. New York, Elsevier

Tzschentke TM, Schmidt WJ (1998): Discrete quinolinic acid lesions of the rat prelimbic medial prefrontal cortex affect cocaine- and MK-801-, but not morphine- and amphetamine-induced reward and psychomotor activation as measured with the place preference conditioning paradigm. Behav Brain Res 97:115-127

Uchimura N, North RA, (1991): Baclofen and adenosine inhibit synaptic potentials mediated by gamma-aminobutyric acid and glutamate release in rat nucleus accumbens. J Pharmacol Exp Ther 258:663-668

Wedzony K, Mackowiak M, Fijal K, Golembiowska K (1996): Evidence that conditioned stress enhances outflow of dopamine in rat prefrontal cortex: A search for the influence of diazepam and 5-HT1A agonists. Synapse 24:240-247

Whitelaw RB, Markou A, Robbins TW, Everitt BJ (1996): Excitotoxic lesions of the basolateral amygdala impair the acquisition of cocaine-seeking behavior under a second-order schedule of reinforcement. Psychopharmacology 127:213-224

Yoshioka M, Matsumoto M, Togashi H, Saito H (1995): Effects of conditioned fear stress on 5-HT release in the prefrontal cortex. Pharmacol Biochem Behav 51:515-519

Yoshioka M, Matsumoto M, Togashi H, Saito H (1996): Effect of conditioned fear stress on dopamine release in the rat prefrontal cortex. Neurosci Lett 209:201-203

Young CD, Deutch AY (1998): The effects of thalamic paraventricular nucleus lesions on cocaine-induced locomotor activity and sensitization. Pharmacol Biochem Behav 60:753-758 